\title{
The ability of a Proteus mirabilis strain to invade the bloodstream is independent of its proticine production/proticine sensitivity type
}

\author{
B. W. SENIOR \\ Department of Medical Microbiology, Dundee University Medical School, Ninewells Hospital, Dundee \\ DD1 9SY
}

\begin{abstract}
Proteus mirabilis strains frequently infect the upper urinary tract and some progress to invade the bloodstream. In an attempt to determine if these were features only of particular strains of $P$. mirabilis, isolates from the blood of 38 unrelated patients, many of whom had an underlying urinary tract infection, and eight from different sources and sites within the upper urinary tract, were analysed by proticine production/proticine sensitivity ( $p / s)$ typing. Twenty-six different $p / s$ types were found among the 38 isolates from blood and seven among the eight isolates from the upper urinary tract. The $p / s$ types found previously to be associated frequently with virulence for the upper urinary tract were not found. Analyses of the frequency of occurrence of the different $\mathrm{p} / \mathrm{s}$ types and of their distribution showed no evidence that the $\mathrm{p} / \mathrm{s}$ characteristics of a $P$. mirabilis strain conferred any advantage on its ability to infect the upper urinary tract or invade the bloodstream.
\end{abstract}

\section{Introduction}

Proteus mirabilis is the micro-organism, after Escherichia coli, most frequently associated with urinary tract infection (UTI), particularly in the elderly [1]. However, unlike $E$. coli which is usually confined to the bladder, $P$. mirabilis appears to have a special predilection for the upper urinary tract $[2,3]$. This may lead to stone formation and acute pyelonephritis.

Certain strains of $P$. mirabilis of a particular proticine production/proticine sensitivity $(\mathrm{p} / \mathrm{s})$ type have been found to be associated more frequently with upper urinary tract infections than bladder infections [1]. It is not yet known if this is because the proticine is associated directly or indirectly with virulence genes or because certain proticine receptors on the bacterial cell surface have affinity for particular chemical groups on tissues of the upper urinary tract. However, it has been shown that the range of fimbriae and haemagglutinins formed by strains of those $p / s$ types associated with infection of the upper urinary tract are not different from those of strains of other $\mathrm{p} / \mathrm{s}$ types $[4]$.

Received 3 Sept. 1996; accepted 11 Oct. 1996. Corresponding author: Dr B. W. Senior.
From time to time, $P$. mirabilis strains also invade the bloodstream and give rise to septicaemia. This is usually a consequence of a prior urinary tract infection or as a result of catheterisation or other surgical manipulation. Proteus bacteraemias are often difficult to treat and have a mortality rate of $15-88 \%$ depending on the severity of the underlying disease [5].

It is not known if $P$. mirabilis strains which invade the bloodstream have special virulence properties and, if so, whether these are similar to or different from those associated with upper urinary tract infections. This matter was examined by comparing the $\mathrm{p} / \mathrm{s}$ types of $P$. mirabilis isolates from blood with those from different sites and types of infection of the urinary tract.

\section{Materials and methods \\ Bacteria \\ Over a period of 19 years, 40 strains of $P$. mirabilis were isolated from the blood of 38 patients (Table 1); 20 were male (mean age 66 years) and 18 were female (mean age 64 years). Many of the patients had clinical evidence of UTI and four died shortly after $P$. mirabilis infection of the blood was reported (Table 1). Eight other strains of $P$. mirabilis were collected over a 5- year period from upper urinary tract sites from seven}


Table 1. Details of $P$. mirabilis isolates from blood

\begin{tabular}{lll}
\hline Strain no. & p/s type & Patient: gender, age (years) and clinical details \\
\hline $46120 \mathrm{Z}$ & $1 / 7,12$ & M 68, pyrexia and UTI, patient died \\
$20506 \mathrm{X}$ & $4 / 0$ & F 46, UTI \\
$92795 \mathrm{Q}$ & $1 / 7$ & F 76 \\
$41288 \mathrm{~S}$ & Atypical/0 & M 84, nephrectomy \\
$39811 \mathrm{Y}$ & $0 / 0$ & F 57 \\
$37799 \mathrm{~A}$ & $0 / 7,9$ & M 85, bronchopneumonia \\
$35022 \mathrm{X}$ & $3 / 5,11,12$ & F 67, pyelonephritis \\
$26387 \mathrm{~K}$ & $3 / 1$ & F 69, subarachnoid haemorrhage \\
$18783 \mathrm{~F}$ & $6 / 2,10$ & M 70, pyrexia, short of breath, patient died \\
$59914 \mathrm{Z}$ & $9 / 13$ & F 26 \\
$11718 \mathrm{~J}$ & $1 / 7$ & M 34, renal failure, pus in urethra \\
$10173 \mathrm{~A}$ & $6 / 2,3,5$ & F 69, chest infection \\
$04117 \mathrm{H}$ & $6 / 2,3,5$ & As above \\
$06283 \mathrm{H}$ & $1 / 7$ & M 78, recent catheterisation of bladder \\
$11720 \mathrm{M}$ & $3 / 0$ & M 64, UTI \\
$18508 \mathrm{U}$ & $2 / 0$ & F 78, medullary sponge kidney, hydronephrosis \\
$16101 \mathrm{~A}$ & $0 / 9,13$ & M 81, stroke, pyrexia \\
$12200 \mathrm{U}$ & $0 / 11$ & M 71, ischaemic foot \\
$08277 \mathrm{G}$ & $0 / 6$ & F 62, permanent catheter, collapse, pyrexia, patient died \\
$23713 \mathrm{~S}$ & $1 / 0$ & F 83, UTI, blocked catheter, patient died \\
$30167 \mathrm{~J}$ & $3 / 13$ & M 54 \\
$26769 \mathrm{~N}$ & $1 / 5,11,12$ & F 71 \\
$11250 \mathrm{U}$ & $7 / 1,5$ & F 68, suspected UTI \\
$16484 \mathrm{~F}$ & $9 / 4,5$ & F 97, pyrexia, UTI \\
$16370 \mathrm{~F}$ & $3 / 0$ & M 70 \\
$09263 \mathrm{D}$ & $2 / 0$ & M 76, pyrexia, UTI \\
$01263 \mathrm{~B}$ & $2 / 0$ & F 54, pyrexia, loin pain, frequency \\
$00814 \mathrm{M}$ & $2 / 0$ & M 88, rigours, UTI \\
$00706 \mathrm{~V}$ & $0 / 0$ & F 79, pyrexia \\
$22816 \mathrm{M}$ & $0 / 0$ & M 81, UTI \\
$09883 \mathrm{~V}$ & Atypical $/ 5$ & M 80, pyrexia, loin pain, UTI \\
$29504 \mathrm{M}$ & $3 / 5,13$ & F 41, pyrexia, catheterised \\
$31207 \mathrm{~B}$ & $0 / 0$ & M 71, pyrexia \\
$13730 \mathrm{G}$ & $3 / 0$ & F 64, pyrexia, UTI \\
$19395 \mathrm{~K}$ & $3 / 0$ & As above \\
$08955 \mathrm{Y}$ & $0 / 7$ & M 30 \\
$18890 \mathrm{~W}$ & $0 / 7$ & M 74, UTI, indwelling catheter, chest infection \\
$12665 \mathrm{~F}$ & $0 / 4$ & F 39 \\
$31977 / 78$ & $9 / 12$ & M 70, transurethral resection of prostate for urine retention \\
$67952 / 77$ & $1 / 0$ & M 2 weeks, pyrexia in premature baby \\
\hline & &
\end{tabular}

women and one man (Table 2) who were unrelated to each other and to the patients with a blood infection. All strains were isolated in purity, confirmed as typical strains of $P$. mirabilis by biochemical tests [6] and stored in screw-capped bottles on nutrient agar slopes at $4^{\circ} \mathrm{C}$.

\section{Proticine production/proticine sensitivity $(p / s)$ typing}

The method used was a modification of that described previously [7]. Proticine (p) production was induced in each isolate (and also in 13 reference strains of Proteus spp. which produce proticines $1-13$ ) by diluting an overnight nutrient broth culture (grown at $37^{\circ} \mathrm{C}$ ) 100 fold in $5 \mathrm{ml}$ of PP3 medium (Proteose Peptone No. 3, Difco, $1 \% \mathrm{w} / \mathrm{v}$ and $\mathrm{NaCl} 0.5 \% \mathrm{w} / \mathrm{v}$ in water and autoclaved at $121^{\circ} \mathrm{C}$ for $15 \mathrm{~min}$ ). After incubation with shaking at $30^{\circ} \mathrm{C}$ for $c .7 \mathrm{~h}$, mitomycin $\mathrm{C}$ (Sigma) was added to each culture to a final concentration of $1 \mu \mathrm{g} /$ $\mathrm{ml}$ and incubation with shaking in the dark continued overnight $(c .16 \mathrm{~h})$. The cultures were then centrifuged at $2000 \mathrm{~g}$ for $10 \mathrm{~min}$ and the clear supernates were transferred to sterile screw-capped bottles. The resultant proticine preparations were sterilised by shaking with a few drops of chloroform and were stored at $4^{\circ} \mathrm{C}$.

Table 2. Details of $P$. mirabilis isolates from sources other than blood

\begin{tabular}{lcl}
\hline Strain no. & $\mathrm{p} / \mathrm{s}$ type & Patient: gender, age (years) and specimen \\
\hline $14267 / 82$ & $0 / 5$ & F 38, pus from left ureter \\
$15997 / 78$ & $3 / 0$ & F 37, swab of renal calyx \\
$18491 / 80$ & $0 / 1$ & F 20, ureteric urine \\
$55306 / 82$ & $0 / 0$ & F 74, pus from left kidney \\
$75843 / 77$ & $5 / 0$ & F 51, swab of calculi in kidney \\
$20536 / 82$ & $1 / 5$ & M 43, aspirate from kidney \\
$32971 / 81$ & $0 / 0$ & F 8, stone from kidney \\
$49704 / 80$ & $2 / 1$ & F 25, stone from ureter \\
\hline
\end{tabular}


The type of proticine produced by each isolate (the $p$ type) was determined by making a streak (without scratching the agar surface) of an overnight nutrient broth culture (grown at $37^{\circ} \mathrm{C}$, or that subsequently stored at $4^{\circ} \mathrm{C}$ ) of each of 13 reference proticine indicator strains of Proteus spp. diametrically across the surface of a dried MacConkey agar plate (Oxoid $\mathrm{CM} 7$ ) (uninoculated plate was incubated overnight at $37^{\circ} \mathrm{C}$ ). Each indicator strain was sensitive to only one type of proticine, and six or seven strains were streaked on each plate. A drop $(c .3 \mu \mathrm{l})$ of each proticine preparation (six or seven different proticine preparations to a plate) from an Eppendorf pipette was placed over each streak of the 13 reference proticinesensitive indicator strains. The plates were then incubated at $37^{\circ} \mathrm{C}$ and after incubation for $2-4 \mathrm{~h}$ were examined under reflected light for areas of inhibition of growth of the indicator strains. This gave the identity of the activity (i.e., the $p$ type) of the proticine produced by the isolate. The proticine sensitivity of each isolate (the s type) was determined in an analogous manner by placing drops of each reference proticine preparation $(\mathrm{p} 1-\mathrm{p} 13)$ over streaks on MacConkey agar plates of nutrient broth cultures of each isolate. After incubation of the plates for 2$4 \mathrm{~h}$ at $37^{\circ} \mathrm{C}$, inhibition of growth by a particular type of reference proticine indicated sensitivity of the isolate to that proticine and hence the $s$ type of the strain.

In each batch of $\mathrm{p} / \mathrm{s}$ typing tests, the activity of the 13 standard proticine preparations, and the sensitivity of the 13 standard proticine indicator strains to them, was verified by testing each to the others in all combinations.

\section{Results}

The $\mathrm{p} / \mathrm{s}$ types of the $P$. mirabilis isolates from blood are presented in Table 1 and those from isolates of the upper urinary tract in Table 2. The distribution and frequency of occurrence of the $\mathrm{p} / \mathrm{s}$ types among the isolates from both sources are presented in Table 3 . Repeat isolates $(04117 \mathrm{H}$ and $19395 \mathrm{~K})$ from two patients, made respectively 19 days and 23 days after the initial ones, are not recorded in Table 3 because in each instance they were of the same $\mathrm{p} / \mathrm{s}$ type as the initial isolate.

Among the 38 single isolates from blood, 26 different $\mathrm{p} / \mathrm{s}$ types were detected. However, $18(47 \%)$ of the 38 patients were infected by only six of these, the commonest ones being $\mathrm{p} 2 / \mathrm{s} 0$ (four patients), $\mathrm{p} 0 / \mathrm{s} 0$ (four patients), p1/s7 (three patients), p3/s0 (three patients), p0/s7 (two patients) and $\mathrm{pl} / \mathrm{s} 0$ (two patients). Each of the four patients with $P$. mirabilis septicaemia who died was infected with strains of different $\mathrm{p} / \mathrm{s}$ types, p1/s7,12, p6/s2,10, p0/s6 and p1/s0.
Among the eight isolates from the upper urinary tract, seven different $\mathrm{p} / \mathrm{s}$ types of strain were found. A large proportion of the isolates from blood and the upper urinary tract, $11(29 \%)$ and $4(50 \%)$ respectively, did not produce a proticine (i.e. were type p0). However, among the isolates from blood that produced a proticine, proticine 1 (seven isolates), 3 (seven isolates) and 2 (four isolates)-producing strains were found most frequently.

A large proportion of the isolates from blood and the upper urinary tract, $15(25 \%)$ and $4(50 \%)$ respectively were not sensitive to any proticine (i.e., were type s0). Among the other isolates, sensitivities to all the proticines except proticine 8 were detected. The most common proticine sensitivity found among the isolates from blood was that to proticine 5 (seven isolates) and proticine 7 (seven isolates).

\section{Discussion}

Proticine production/proticine sensitivity $(\mathrm{p} / \mathrm{s})$ typing is the most discriminating method for typing $P$. mirabilis [1] and is independent of other typing schemes such as $O$ serotyping [8]. It has been found to be a stable and reproducible method and this was confirmed here with the repeat blood isolates from two patients and the finding (data not shown) that the $p / s$ types of those strains retyped after many years in storage remained unchanged.

When the typing method was applied in the past [1] to investigate the type of $P$. mirabilis strains associated with UTI, it was found that, although 97 different $\mathrm{p} / \mathrm{s}$ types were found among $241 \mathrm{P}$. mirabilis isolates from urine, $14 \%$ of the strains were of only three $\mathrm{p} / \mathrm{s}$ types: $\mathrm{p} 3 / \mathrm{s} 1,8 ; \mathrm{p} 3 / \mathrm{s} 1,13$ and $\mathrm{p} 3 / \mathrm{s} 1,8,13$. Strains of these $\mathrm{p} / \mathrm{s}$ types appeared to have a special affinity for the upper urinary tract because they were found more frequently than could be accounted for on the basis of carriage rate in the faeces of healthy elderly people, and they were almost exclusively associated with patients having symptoms of upper urinary tract infection such as loin pain, pyrexia and haematuria. Most of the other $\mathrm{p} / \mathrm{s}$ types were associated with cystitis or symptomless UTI [1].

The virulence of strains with the above $p / s$ types may be because the proticine directly or indirectly is associated with virulence as is colicin in colicin Vproducing $E$. coli strains [9]. In addition, or alternatively, because proticines bind to receptors at the bacterial cell surface (unpublished observations), the proticine sensitivity type may characterise a particular type of cell surface associated with either affinity for particular tissues or with increased resistance to immunological processes. The analysis of the $\mathrm{p} / \mathrm{s}$ types of $P$. mirabilis strains isolated from 


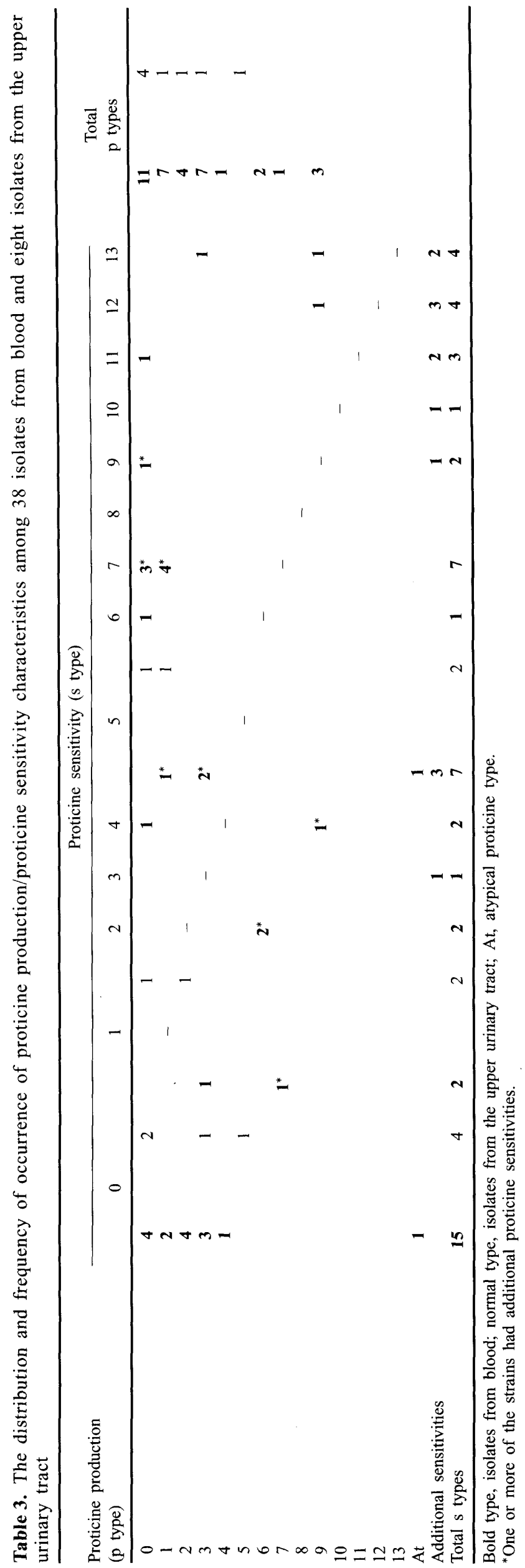


blood and those associated with infection at different sites in the upper urinary tract permitted further investigation of an association between the $\mathrm{p} / \mathrm{s}$ type of a P. mirabilis strain and its virulence for man.

It may be significant that although 26 different $\mathrm{p} / \mathrm{s}$ types were found among the 38 isolates from blood and seven $\mathrm{p} / \mathrm{s}$ types among the eight isolates from the upper urinary tract, no isolate had one of the above three $\mathrm{p} / \mathrm{s}$ types previously associated with virulence for the upper urinary tract. Moreover, the $\mathrm{p} / \mathrm{s}$ types of the strains isolated from blood from patients shortly before they died were all different. All these factors indicate many different types of strain can invade the upper urinary tract and later the bloodstream and they suggest that the virulence of $P$. mirabilis strains is not associated with the $\mathrm{p} / \mathrm{s}$ type of the strain. Thus, the finding in the past of an association between strains of $\mathrm{p} 3 / \mathrm{s} 1,8$ and related $\mathrm{p} / \mathrm{s}$ types with upper urinary tract infection would have to be explained, as was noted at the time, on the basis that they were difficult to eradicate from the urinary tract because of multiple resistance to antibiotics [1].

If proticine production in general, or a given proticine in particular, is associated with virulence it would be anticipated that in the isolates studied, most, if not all, would be proticine producers or a particular proticine would be predominant. However, only $50 \%$ of the upper urinary tract isolates and $71 \%$ of the blood isolates produced a proticine, proportions certainly not greater than the $65 \%$ proticine producers found in normal faeces of healthy elderly people and the $75 \%$ found in undefined infections of the urinary tract [1].

In surveys of the $\mathrm{p} / \mathrm{s}$ types of strains found in urine, normal faeces, pus and other clinical specimens $[1,7,8]$, the most commonly encountered strains are those that produce proticines 1 or 2 or 3 . Strains producing these proticines were also the commonest among the blood isolates and were formed by $46 \%$ of them, a proportion not very different from the $42 \%$ of strains from infected urine found previously to produce these proticines [1]. Moreover, the frequency of detection of producers of other types of proticine among the blood isolates was similarly not very different from that found previously among isolates from urine [1]. This would suggest that the ability of a strain to produce a particular type of proticine, or indeed any type of proticine, does not confer on it an advantage in ability to invade the bloodstream. Among the isolates from blood, there was not one proticine formed more frequently than the others, and producers of proticines 1 and 3 , followed by proticine 2, remained the commonest isolates.

If the virulence of a strain is dependent upon its proticine sensitivity, then it would be expected that most of the isolates would have been sensitive to proticines in general or to a small number of proticines in particular. However, the study revealed that $15(25 \%)$ and four $(50 \%)$ of those from blood and the upper urinary tract respectively were not sensitive to any proticine. Moreover, excepting sensitivity to proticine 8 which was not detected, sensitivity to the remaining 12 proticines was fairly evenly distributed among the isolates. These are strong indications that the proticine sensitivity type of a strain does not confer an advantage on its ability to invade the bloodstream.

The sensitivity of an isolate to a proticine is dependent on the formation of specific receptors found on the outer surface of the cell (unpublished observations). Serum resistance, like proticine sensitivity, is also influenced largely by the structure of the outer surface of the cell. It is probable that many of the isolates from blood were serum resistant. However, because Larsson and Olling [10] have shown that $88 \%$ of Proteus isolates from blood of a wide range of common $\mathrm{O}$ serotypes were serum resistant although they did not possess capsular $\mathrm{K}$ antigens, it is unlikely that the serum-resistant strains in this study were confined to those $25 \%$ that did not possess proticine receptors and were, therefore, proticine insensitive. Moreover, as $\mathrm{p} / \mathrm{s}$ typing is also independent of $\mathrm{O}$ serotyping [8], it is probable that serum resistance was present among many of the other strains of diverse proticine sensitivity, irrespective of their $O$ serotypes. This probable lack of association between the proticine sensitivity type of a strain and serum resistance again suggests that proticine sensitivity does not confer an advantage for invasion of the bloodstream.

P. mirabilis is known to possess various virulence determinants and mechanisms. Among these are urease [11], fimbriae [12-14], haemolysins [15-17], flagella and swarming $[18,19]$ and proteinase [20-22]. None of these determinants has yet been shown to be associated with any particular $\mathrm{p} / \mathrm{s}$ type $[4,16,23-25]$. All these factors together indicate that neither the proticine type nor the proticine sensitivity type of a P. mirabilis strain has any bearing on its virulence properties.

\section{References}

1. Senior BW. The special affinity of particular types of Proteus mirabilis for the urinary tract. $J$ Med Microbiol 1979; 12:1-8.

2. Fairley KF, Grounds AD, Carson NE et al. Site of infection in acute urinary-tract infection in general practice. Lancet 1971; 2: 615-618.

3. Svanborg Edén C, Larsson P, Lomberg H. Attachment of Proteus mirabilis to human urinary sediment epithelial cells in vitro is different from that of Escherichia coli. Infect Immun 1980; 27: 804-807.

4. Adegbola RA, Old DC, Senior BW. The adhesins and fimbriae of Proteus mirabilis strains associated with high and low affinity for the urinary tract. $J$ Med Microbiol 1983; 16: $427-431$.

5. Lewis J, Feckety FR. Proteus bacteremia. Johns Hopkins Med $J$ 1969; 124: 151-156.

6. Senior BW. Media and tests to simplify the recognition and identification of members of the Proteeae. $J$ Med Microbiol 1997; 46: 39-44. 
7. Senior BW. Typing of Proteus strains by proticine production and sensitivity. $J$ Med Microbiol 1977; 10: 7-17.

8. Senior BW, Larsson P. A highly discriminatory multi-typing scheme for Proteus mirabilis and Proteus vulgaris. J Med Microbiol 1983; 16: 193-202.

9. Smith HW, Huggins MB. Further observations on the association of the colicine $\mathrm{V}$ plasmid of Escherichia coli with pathogenicity and with survival in the alimentary tract. $J$ Gen Microbiol 1976; 92: 335-350.

10. Larsson P, Olling S. O antigen distribution and sensitivity to the bactericidal effect of normal human serum of Proteus strains from clinical specimens. Med Microbiol Immunol 1977; 163: $77-82$.

11. Johnson DE, Russell RG, Lockatell CV, Zulty JC, Warren JW, Mobley HLT. Contribution of Proteus mirabilis urease to persistence, urolithiasis, and acute pyelonephritis in a mouse model of ascending urinary tract infection. Infect Immun 1993; 61: $2748-2754$.

12. Bahrani FK, Massad G, Lockatell CV et al. Construction of an MR/P fimbrial mutant of Proteus mirabilis: role in virulence in a mouse model of ascending urinary tract infection. Infect Immun 1994; 62: 3363-3371.

13. Massad G, Lockatell CV, Johnson DE, Mobley HLT. Proteus mirabilis fimbriae: construction of an isogenic pmfA mutant and analysis of virulence in a CBA mouse model of ascending urinary tract infection. Infect Immun 1994; 62: $536-542$.

14. Sareneva T, Holthöfer H, Korhonen TK. Tissue-binding affinity of Proteus mirabilis fimbriae in the human urinary tract. Infect Immun 1990; 58: 3330-3336.

15. Peerbooms PGH, Verweij AMJJ, MacLaren DM. Vero cell invasiveness of Proteus mirabilis. Infect Immun 1984; 43: $1068-1071$.
16. Senior BW, Hughes C. Production and properties of haemolysins from clinical isolates of the Proteeae. $J$ Med Microbiol 1988; 25: $17-25$.

17. Chippendale GR, Warren JW, Trifillis AL, Mobley HLT. Internalization of Proteus mirabilis by human renal epithelial cells. Infect Immun 1994; 62: 3115-3121.

18. Allison C, Lai H-C, Hughes C. Co-ordinate expression of virulence genes during swarm-cell differentiation and population migration of Proteus mirabilis. Mol Microbiol 1992; 6: $1583-1591$

19. Allison C, Coleman N, Jones PL, Hughes C. Ability of Proteus mirabilis to invade human urothelial cells is coupled to motility and swarming differentiation. Infect Immun 1992; 60: 4740-4746.

20. Senior BW, Loomes LM, Kerr MA. The production and activity in vivo of Proteus mirabilis IgA protease in infections of the urinary tract. J Med Microbiol 1991; 35: 203-207.

21. Loomes LM, Kerr MA, Senior BW. The cleavage of immunoglobulin $\mathrm{G}$ in vitro and in vivo by a proteinase secreted by the urinary tract pathogen Proteus mirabilis. J Med Microbiol 1993; 39: 225-232.

22. Loomes LM, Senior BW, Kerr MA. Proteinases of Proteus spp.: purification, properties and detection in urine of infected patients. Infect Immun 1992; 60: 2267-2273.

23. Senior BW, Bradford NC, Simpson DS. The ureases of Proteus strains in relation to virulence for the urinary tract. $J \mathrm{Med}$ Microbiol 1980; 13: 507-512.

24. Senior BW, Albrechtsen M, Kerr MA. Proteus mirabilis strains of diverse type have IgA protease activity. $J$ Med Microbiol 1987; 24: 175-180.

25. Senior BW, Albrechtsen M, Kerr MA. A survey of IgA protease production among clinical isolates of Proteeae. $J \mathrm{Med}$ Microbiol 1988; 25: 27-31. 